\title{
Pharmacological properties of a C-fibre response evoked by saphenous nerve stimulation in an isolated spinal cord-nerve preparation of the newborn rat
}

\author{
Jean-Claude Nussbaumer, Mitsuhiko Yanagisawa \& ${ }^{1}$ Masanori Otsuka \\ Department of Pharmacology, Faculty of Medicine, Tokyo Medical and Dental University, Bunkyo-ku, \\ Tokyo 113, Japan
}

1 An isolated spinal cord-peripheral nerve preparation of the newborn rat was developed. In this preparation it is possible to record spinal reflexes from a lumbar ventral root in response to stimulation of the ipsilateral saphenous or obturator nerve.

2 Single shock, weak intensity stimulation of the saphenous nerve induced a fast conducted compound action potential in the L3 dorsal root and a fast depolarizing response in the ipsilateral L3 ventral root. As a stronger stimulus was applied to the saphenous nerve, a slowly conducted compound action potential appeared in the dorsal root and a slow depolarizing ventral root potential (v.r.p.) in the L3 ventral root.

3 Single shock stimulation of the obturator nerve induced a rapidly conducted compound action potential in the L3 dorsal root and monosynaptic and polysynaptic reflexes, with a fast time course, in the ipsilateral $\mathrm{L} 3$ ventral root.

4 The slow v.r.p. evoked by saphenous nerve stimulation was depressed by the tachykinin antagonist, [D-Arg ${ }^{1}, D_{-T r p}{ }^{7,9}$, Leu $^{11}$ ] substance P (spantide), 4-16 $\mu \mathrm{M}$. The response recovered its original shape and size 30-60 min after the removal of this antagonist.

5 The saphenous nerve-evoked slow v.r.p. was depressed by $\left[\mathrm{Met}^{5}\right]$ enkephalin $(0.1-1 \mu \mathrm{M})$, dynorphin $(1-13)(0.2 \mu \mathrm{M})$ and morphine $(1-2 \mu \mathrm{M})$, and these effects were reversed by naloxone $(1 \mu \mathrm{M})$.

6 Two endogenous peptides, galanin (1-2 $\mu \mathrm{M})$ and somatostatin $(1-2.5 \mu \mathrm{M})$, inhibited the slow v.r.p. evoked by saphenous nerve stimulation, whereas another endogenous peptide, calcitonin generelated peptide $(0.1-0.5 \mu \mathrm{M})$, potentiated the slow v.r.p. The slow v.r.p. was also inhibited by $\gamma$ aminobutyric acid $(\mathrm{GABA}, 20 \mu \mathrm{M})$ and muscimol $(0.2 \mu \mathrm{M})$, and their effects were antagonized by bicuculline $(1 \mu \mathrm{M})$.

7 The present results suggest that substance $P$ and neurokinin $A$ are involved in the saphenous nerve-evoked $\mathrm{C}$-fibre response in the spinal cord of the newborn rat.

\section{Introduction}

The tachykinin antagonist, [D-Arg ${ }^{1}, \mathrm{D}^{\circ} \operatorname{Trp}^{7,9}$, $\mathrm{Leu}^{11}$ ] substance $\mathrm{P}$ (spantide) (Rosell, 1986), depresses the nociceptive reflex induced by application of capsaicin to the tail of an isolated spinal cord-tail preparation of the newborn rat (Otsuka \& Yanagisawa, 1988). Based on this finding, as well as many other lines of evidence, we suggested that substance P (SP) and neurokinin A (NKA), which are present in a subpopulation of primary afferent $C$ fibres, are involved as neurotransmitters in this nociceptive reflex. We assumed that the nociceptive reflex was induced by stimulation of primary afferent $C$

\footnotetext{
${ }^{1}$ Author for correspondence.
}

fibres, basing our assumption entirely on the pharmacological specificity of capsaicin (Kenins, 1982; Heyman \& Rang, 1985; Marsh, 1985). Indeed, we were not able to prove, by recording from sensory nerves, that the application of capsaicin resulted in an afferent $\mathrm{C}$-fibre volley which induced the nociceptive reflex. In the present study we used a newly developed isolated spinal cord-peripheral nerve preparation of the newborn rat in which a purely cutaneous nerve, i.e. the saphenous nerve, and a typical muscle nerve, i.e. the obturator nerve, can be separately stimulated. Electrical stimulation of saphenous nerve at $C$-fibre strength evoked a slow ventral root depolarization similar to that evoked by 
a

A

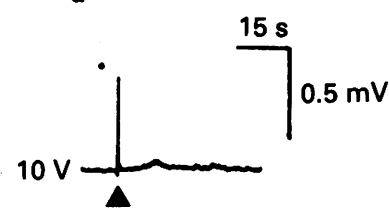

B

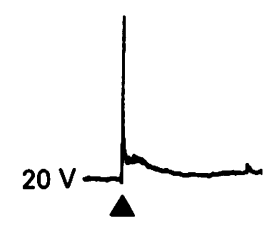

C

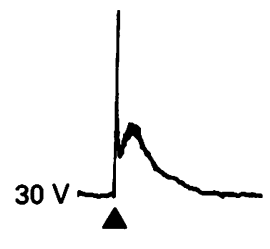

D

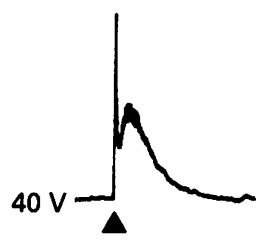

b
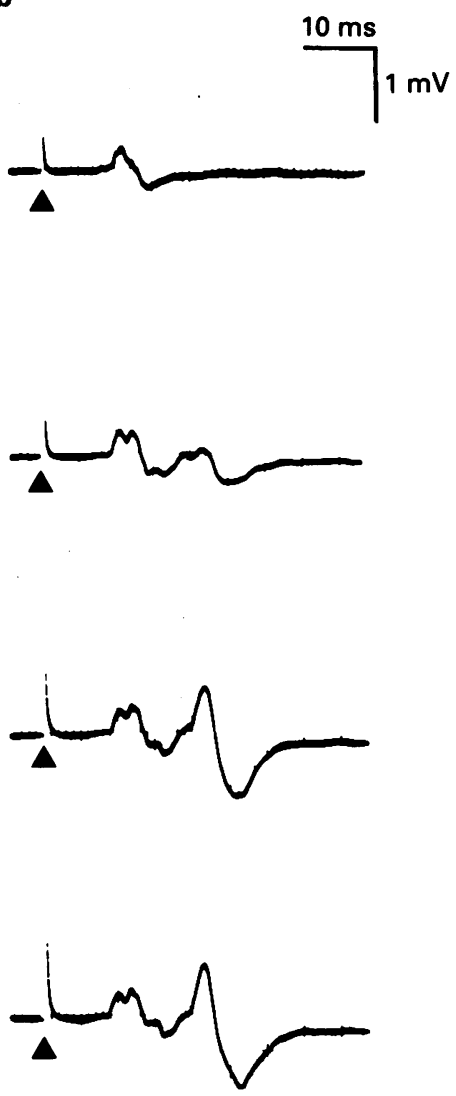

$\mathbf{E}$

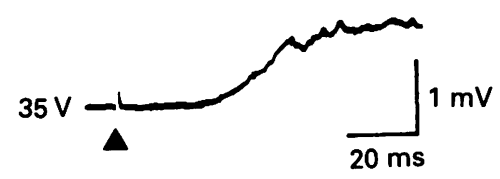

Figure 1 Effects of stimulation of the saphenous nerve. Isolated spinal cord-peripheral nerve preparation of a 3 day-old rat. The nerve was stimulated with single shocks of $200 \mu$ s duration and increasing intensities at $\Delta$. The intensities are indicated on the left side of the records. At first the potentials from the ipsilateral L3 ventral root were monitored on a pen-recorder (Aa-Da). In (E) part of the response of the ventral root is displayed with a fast sweep speed on an oscilloscope. Then the $\mathrm{L} 3$ dorsal root was cut at the point of entry into the spinal cord and the potentials were recorded on an oscilloscope from the cut distal end of the dorsal root (b). Calibrations in (A) apply to (A-D).

the application of capsaicin to the tail (Otsuka \& Yanagisawa, 1988). We therefore used this preparation to test the effects of spantide and other drugs on a response with a slow time course evoked by electrical stimulation of $\mathbf{C}$ fibres. Some of the present results have been published in a preliminary form (Otsuka \& Yanagisawa, 1987b).

\section{Methods}

Neonatal Wistar rats aged 1-4 days were anaesthetised with ether, decapitated and placed in a dissecting dish perfused with oxygenated artificial cerebrospinal fluid (CSF; for composition see Akagi et al., 1985) at room temperature. After the removal 
of visceral organs, a ventral laminectomy was performed and the dural sac opened in order to expose the spinal cord to $\mathrm{O}_{2}$ and the nutrients contained in the artificial CSF. The inguinal ligament was then resected exposing the distal end of the psoas muscle with the femoral nerve lying laterally to it. Resection of the psoas muscle exposed the thick nervous trunk which gives rise to the femoral and obturator nerves. The obturator nerve was sectioned at the level of the obturator foramen and dissected free. The saphenous nerve was sectioned where it runs superficially over the medial aspect of the knee joint, and was dissected free up to its origin from the femoral nerve (for anatomical data, see Greene, 1968).

The spinal cord, without hemisection below the lower thoracic level, together with the lumbar ventral and dorsal roots, dorsal root ganglia (L3-4), and the attached femoral, saphenous and obturator nerves on one side, was dissected out, placed in a recording chamber of about $0.4 \mathrm{ml}$ volume and perfused with artificial CSF saturated with $95 \% \mathrm{O}_{2} / 5 \%$ $\mathrm{CO}_{2}$ at a rate of about $6 \mathrm{ml} \mathrm{min}^{-1}$. The temperature was kept at $27^{\circ} \mathrm{C}$.

Extracellular recordings were made from the L3 ventral root or from the distal end of the cut dorsal root with a tightly fitting suction electrode on a penrecorder or an oscilloscope through a preamplifier. Details of the experimental procedures and the sources of drugs were as described previously (Otsuka \& Yanagisawa, 1988).

\section{Results}

\section{Effects of stimulation of the saphenous and obturator nerves}

In the experiment illustrated in Figure 1, the saphenous nerve was stimulated with single shocks of $200 \mu$ s duration and increasing intensity, and the responses were recorded from the ipsilateral L3 ventral root. At a stimulus intensity of $10 \mathrm{~V}$, a depolarizing response lasting about $200 \mathrm{~ms}$ was induced (Figure 1Aa). When the stimulus intensity was increased to $30 \mathrm{~V}$, a slow depolarizing response lasting 20-30s was elicited (Figure 1Ca). After these observations, the L3 dorsal root was severed at the entrance to the spinal cord and the incoming afferent volley was recorded from the peripheral stump of the dorsal root with a suction electrode, while the position of the saphenous nerve in the stimulating suction electrode was left unchanged. When the saphenous nerve was stimulated with a stimulus intensity of $10 \mathrm{~V}$, a rapidly conducted compound action potential was recorded from the dorsal root (Figure $1 \mathrm{Ab})$, which corresponded to the depolarizing response with a fast time course recorded from the ventral root. At a stimulus intensity of $30 \mathrm{~V}$, a slowly conducted wave was recorded (Figure $1 \mathrm{Cb}$ ), which corresponded to the response with a slow time course recorded from the ventral root. We estimated the conduction velocity of the rapidly conducted wave to be about $1 \mathrm{~ms}^{-1}$, a speed which would be expected in A fibres. The slowly conducting wave had an estimated conduction velocity of $0.5 \mathrm{~ms}^{-1}$, a speed that would be expected in $\mathrm{C}$ fibres (Fitzgerald \& Gibson, 1984; Fitzgerald, 1985).

Stimulation of the obturator nerve with increasing intensity, elicited a response in the ipsilateral ventral root when the intensity of the stimuli attained a value of $15 \mathrm{~V}$ (Figure $2 \mathrm{Ba}$ ). When the potential was recorded from the peripheral stump of the severed L3 dorsal root, a compound action potential with a conduction velocity of about $1.2 \mathrm{~ms}^{-1}$ was observed at a stimulus intensity of $15 \mathrm{~V}$ (Figure $2 \mathrm{Bb}$ ). With stimuli of varying intensities a close correlation between the amplitude of the compound action potential in the dorsal root and the size of the evoked response in the ventral root was observed (Figure 2A-D). The short delay suggests that the initial response in the ventral root is a monosynaptic reflex. There is evidence that monosynaptic reflexes evoked by Ia muscle afferents are already developed at the time of birth of rats (Saito, 1979; Konishi, 1982; Kudo \& Yamada, 1985). Saphenous nerve stimulation, by contrast, did not evoke a monosynaptic reflex in the L3 ventral root as shown in Figure 1E with a fast sweep speed.

Recordings from ventral roots with a slow time base showed that stimulation of the obturator nerve elicited a depolarizing response with a relatively fast time course, which, even with intense stimulation, was followed by a slow depolarization of small amplitude (Figure 2E). In this paper, therefore, we present data about effects of drugs on the slow response evoked by stimulation of a cutaneous nerve only. Single or double shocks at $20-50 \mathrm{~Hz}$ were used for stimulation. Stable responses could be recorded from the ventral root for several hours.

\section{Effects of spantide on the saphenous nerve-evoked slow response}

Since the above experiments suggested that the slow depolarizing response of the ventral root upon intense stimulation of the saphenous nerve was evoked by primary afferent $C$ fibres, it was of interest to examine the possible involvement in this reflex of SP and NKA which are contained in certain primary afferent C fibres (Nagy et al., 1981; Leah et al., 1985; Hua et al., 1985). We therefore tested the effects of spantide, which has been shown to be a specific and 
8

A<smiles>[124OH]</smiles>

B

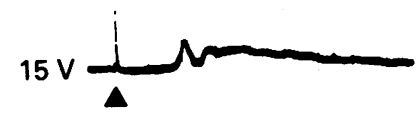

C

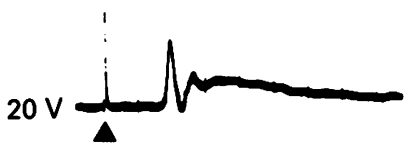

D

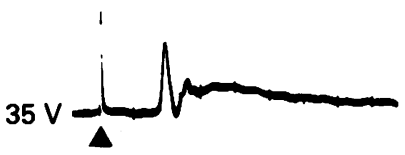

b

$\stackrel{20 \mathrm{~ms}}{1 \mathrm{mV}}$
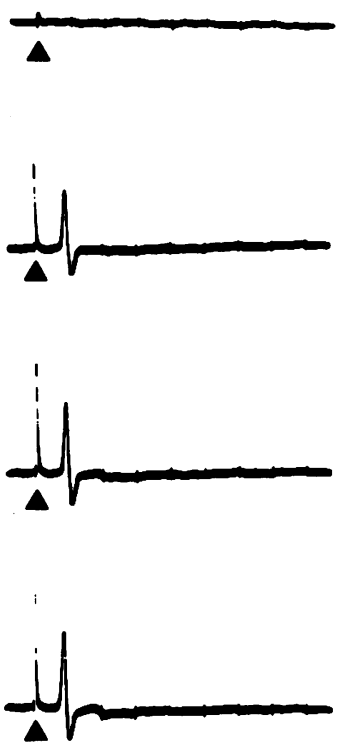

E

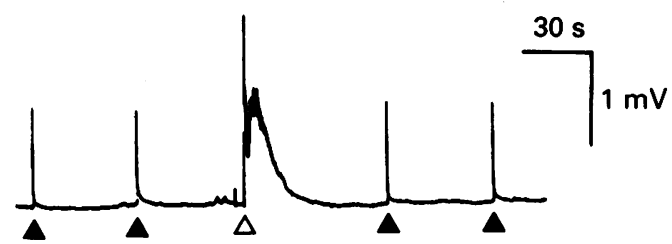

Figure 2 Effects of stimulation of the obturator nerve. The same preparation as in Figure 1 was used except in (E). The nerve was stimulated at $\Delta$ with single square pulses of $200 \mu$ s duration and increasing intensities, which are indicated on the left side of the records. Other details of the experimental procedures are the same as for Figure 1. (a) Records from the L3 ventral root. (b) Records from the L3 dorsal root. Time and voltage scales in (Ab) apply to both (a) and (b) except (E). In (E) the responses of the ventral root to supramaximal stimulation of obturator (A) and saphenous $(\Delta)$ nerves are monitored on a pen-recorder with a slow time scale.

effective tachykinin antagonist (Otsuka \& Yanagisawa, 1988), on the saphenous nerve-evoked slow ventral root potential (v.r.p.). Perfusion of the preparation with spantide at a concentration of $16 \mu \mathrm{M}$ markedly depressed the slow v.r.p. and recovery occurred 30-60 min after removal of the antagonist (Figure 3). Similar depressant effects of spantide (4$16 \mu \mathrm{M})$ were observed in 4 other preparations.

Surprenant et al. (1987) showed that [D-Arg', D-Pro ${ }^{2}$, D-Trp ${ }^{7,9}$, Leu ${ }^{11}$ ]substance $P$, a tachykinin antagonist with a structure closely related to spantide, causes release of noradrenaline in guinea-pig submucosal plexus. It was conceivable, therefore, that the effect of spantide as illustrated in Figure 3, might be due to a release of some inhibitory trans- mitters. However, the depressant effect of spantide on the saphenous nerve-evoked C-fibre response was as clearly observed in the presence of naloxone $(0.5 \mu \mathrm{M})$, bicuculline $(0.5 \mu \mathrm{M})$ or prazosin $(1 \mu \mathrm{M})$ as in the absence of these antagonists.

Post et al. (1985) found that two substance P analogues with tachykinin antagonist activity have a potent local anaesthetic action. It might therefore be argued that spantide inhibited the slow v.r.p. through its depressant action on the afferent input in the present preparation. However, upon stimulation of the saphenous and obturator nerves the compound action potentials recorded from the cut dorsal root were not at all affected by $16 \mu \mathrm{M}$ spantide. Furthermore, both the monosynaptic reflex evoked by 


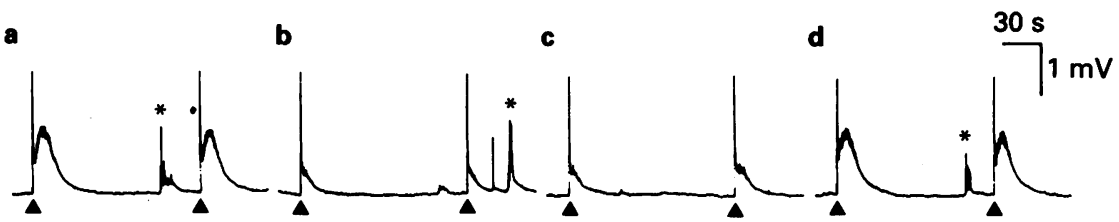

Figure 3 Effect of spantide on the reflex responses evoked by saphenous nerve stimulation. Isolated spinal cordperipheral nerve preparation of a 1 day-old rat. Potentials were recorded from an $\mathbf{L} 3$ ventral root and the ipsilateral saphenous nerve was stimulated every $2 \mathrm{~min}$ at $\Delta$ with double square pulses of $100 \mu \mathrm{s}$ duration and supramaximal intensity at $20 \mathrm{~Hz}$. (a) Control responses, (b) $3 \mathrm{~min}$ after adding $16 \mu \mathrm{M}$ spantide, (c) and (d) are $10 \mathrm{~min}$ and $42 \mathrm{~min}$, respectively, after removal of spantide. In each record two consecutive responses are shown. Asterisks indicate spontaneous activity.

stimulation of obturator nerve and the saphenous nerve-evoked depolarizing v.r.p. of fast time course were little affected by spantide $16 \mu \mathrm{M}$ (Figure 3).

\section{Effects of endogenous peptides, $\gamma$-aminobutyric acid and related drugs}

We have further studied the effects of several endogenous peptides, $\gamma$-aminobutyric acid (GABA) and related drugs to examine their possible physiological roles in the spinal cord. In the experiment shown in Figure 4, the effects of opioids were examined. The saphenous nerve-evoked slow v.r.p. was markedly depressed by [ $\left[\mathrm{Met}^{5}\right]$ enkephalin $(0.1-1 \mu \mathrm{M}$; number of preparations $(n)=3)$, dynorphin (1-13) $(0.2 \mu \mathrm{M}$; $n=3)$ and morphine $(1-2 \mu \mathrm{M} ; n=2)$. The effect of $\left[\mathrm{Met}^{5}\right]$ enkephalin disappeared after the peptide was washed out, which led to a transient enhancement of the magnitude of the reflex (Figure 4Ac). The effects of dynorphin (1-13) and morphine, by contrast, were sustained for more than $30 \mathrm{~min}$ after removal of the drugs. These effects of opioids were reversed by naloxone $(1 \mu \mathrm{M})$ (Figure $4 \mathrm{Bc})$. Application of naloxone $(0.5 \mu \mathrm{M})$ alone to fresh preparations which had not received any opioids previously, markedly potentiated the saphenous nerve-evoked slow v.r.p. (cf. Yanagisawa et al., 1984).

As shown in Figure 5, two other endogenous neuropeptides, galanin $(1-2 \mu \mathrm{M} ; n=2)$ and somatostatin (1-2.5 $\mu \mathrm{M} ; n=3)$, also depressed markedly and reversibly the saphenous nerve-evoked slow v.r.p. By contrast, calcitonin gene-related peptide (CGRP; $0.1-0.5 \mu \mathrm{M} ; n=5$ ) reversibly potentiated the saphenous nerve-evoked slow v.r.p. (Figure 6).

Figure 7 shows the effects of GABA $(20 \mu \mathrm{M} ; n=4)$ and the GABA $\mathrm{A}_{\mathrm{A}}$-receptor agonist, muscimol $(0.2 \mu \mathrm{M}$; $n=2$ ) on the saphenous nerve-evoked slow v.r.p. which was depressed by these drugs. These effects were reversed by either washing out the drugs or by

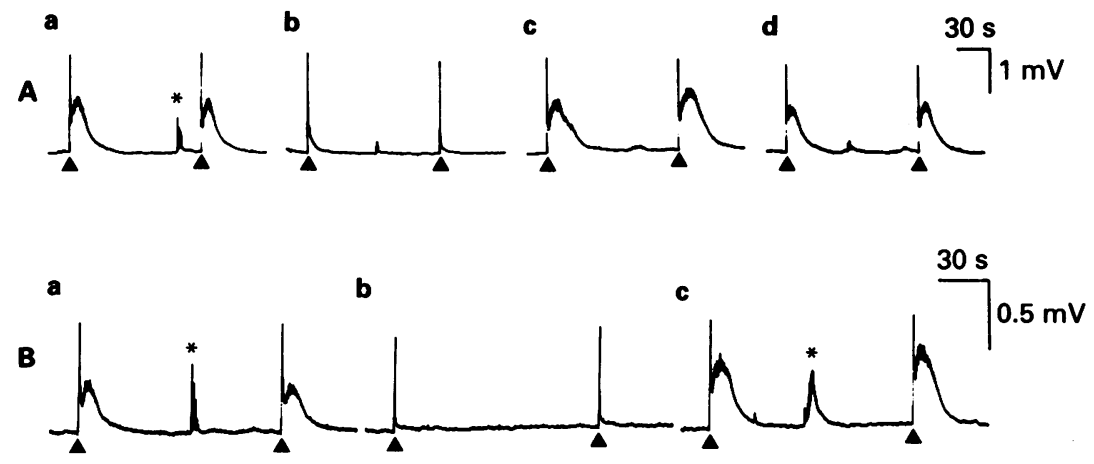

Figure 4 Effects of opioids and naloxone on the reflex responses evoked by saphenous nerve stimulation. Isolated

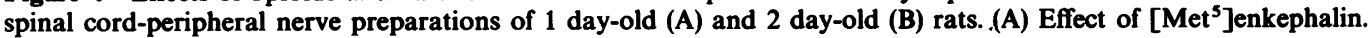
Potentials were recorded extracellularly from an $\mathrm{L} 3$ ventral root upon stimulation of the ipsilateral saphenous nerve every 2 min at $\Delta$ with double square pulses of $100 \mu$ s duration and supramaximal intensity at $50 \mathrm{~Hz}$. (a) Control, (b) $1 \mathrm{~min}$ after adding $1 \mu \mathrm{M}$ [Met ${ }^{5}$ ]enkephalin, (c) and (d) are $1 \mathrm{~min}$ and $5 \mathrm{~min}$, respectively, after removal of [Met $\left.{ }^{5}\right]$ enkephalin. (B) Effects of morphine and naloxone. Experimental procedures are the same as for (A). (a) Control, (b) $5 \mathrm{~min}$ after adding $2 \mu \mathrm{M}$ morphine, (c) $3 \mathrm{~min}$ after further addition of $1 \mu \mathrm{M}$ naloxone in the continuous presence of $2 \mu \mathrm{M}$ morphine. In each record 2 consecutive responses are shown. Asterisks indicate spontaneous activity. 


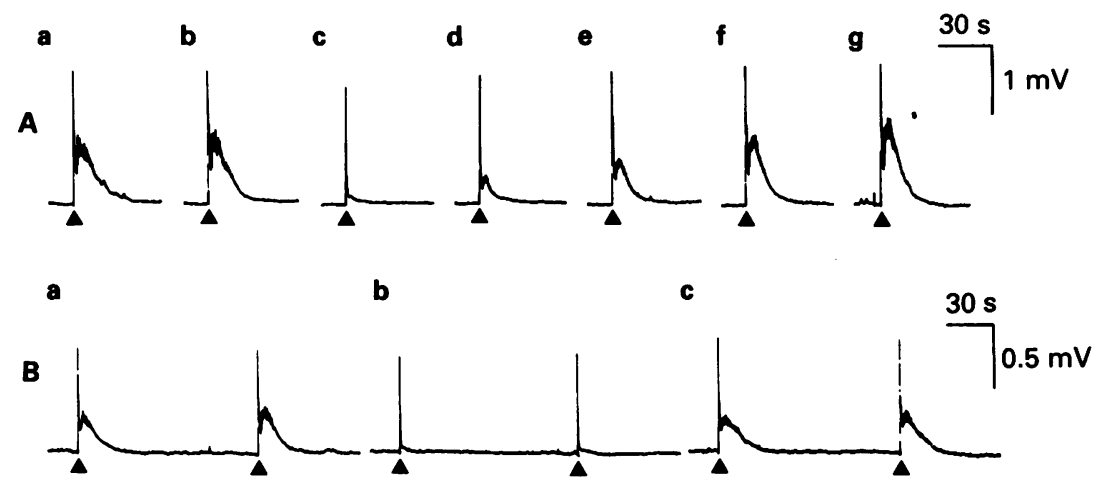

Figure 5 Effects of galanin and somatostatin on the reflex responses evoked by saphenous nerve stimulation. Isolated spinal cord-peripheral nerve preparations of 2 day-old rats. Potentials were recorded extracellularly from L3 ventral roots and the ipsilateral saphenous nerve was stimulated every $4 \mathrm{~min}$ (A) or 2 min (B) at $\Delta$ with double square pulses of $100 \mu \mathrm{s}$ duration and supramaximal intensity at $50 \mathrm{~Hz}$. (A) Effect of galanin. (a) and (b) Controls, (c) $2 \mathrm{~min}$ after adding $2 \mu \mathrm{M}$ galanin, (d), (e), (f) and (g) are 3, 7, 15, and $23 \mathrm{~min}$, respectively, after removal of galanin. (B) Effect of somatostatin. (a) Conrol; (b) 2 min after adding $2.5 \mu \mathrm{M}$ somatostatin, (c) $65 \mathrm{~min}$ after removal of the peptide. In (B) each record shows two consecutive responses.

bicuculline $(1 \mu \mathrm{M})$. In addition, GABA exerted a slight depolarizing action on the ventral root.

The saphenous nerve-evoked fast v.r.p. was not affected by calcitonin gene-related peptide (CGRP, $1 \mu \mathrm{M})$, but slightly depressed by $\left[\mathrm{Met}^{5}\right]$ enkephalin $(1 \mu \mathrm{M})$, dynorphin $(1-13)(0.2 \mu \mathrm{M})$, morphine $(2 \mu \mathrm{M})$,
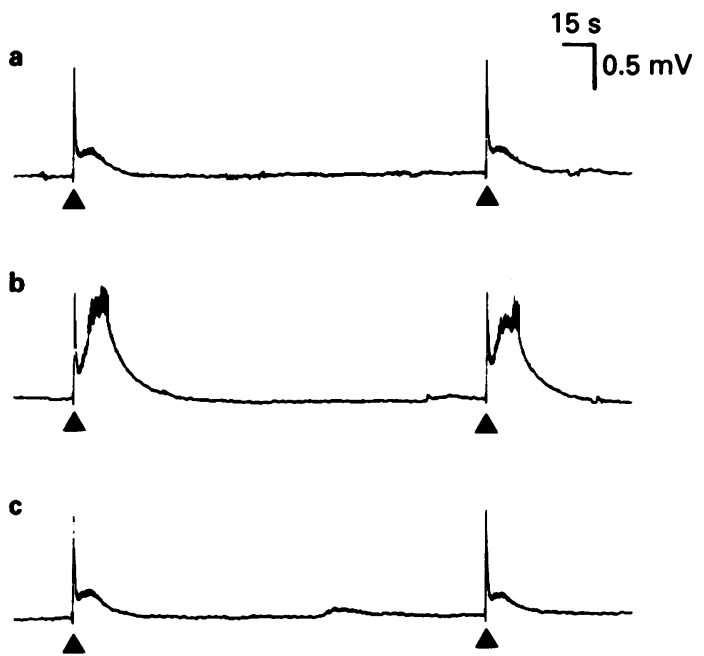

Figure 6 Effects of calcitonin gene-related peptide (CGRP) on the reflex responses evoked by saphenous nerve stimulation. Isolated spinal cord-peripheral nerve preparation of a 2 day-old rat. Recordings are as in Figures 3-5. Ipsilateral saphenous nerve was stimulated every $3 \mathrm{~min}$ at $\Delta$ with double square pulses of $150 \mu \mathrm{s}$ duration and supramaximal intensity at $50 \mathrm{~Hz}$. (a) Control, (b) $4 \mathrm{~min}$ after adding $0.2 \mu \mathrm{M}$ CGRP, (c) $30 \mathrm{~min}$ after removal of the peptide. galanin $(2 \mu \mathrm{M})$, somatostatin $(2.5 \mu \mathrm{M})$, GABA $(20 \mu \mathrm{M})$ and muscimol $(0.2 \mu \mathrm{M})$. The obturator nerve-evoked monosynaptic reflex was little affected by these drugs at the above concentrations.

\section{Discussion}

Intense stimulation of a cutaneous, i.e. saphenous, nerve which contains more than $80 \%$ of unmyelinated fibres (Jancsó et al., 1985), induces a slowly conducted afferent volley in the $\mathbf{L} 3$ dorsal root which is presumably attributable to $\mathrm{C}$ fibres (Fitzgerald, 1985), and at the same time a slow depolarizing response in the ipsilateral ventral root. The functional significance of the saphenous nerve-evoked slow v.r.p. is at present unknown, but may be related to various $\mathrm{C}$ fibre-evoked activities of spinal neurones. In rats, flexor-withdrawal reflexes can be evoked by cutaneous C-fibre stimulation at birth (Fitzgerald \& Gibson, 1984). These reflexes are exaggerated and of long duration in the neonatal period (Ekholm, 1967; Fitzgerald \& Gibson, 1984). Our preliminary experiments with the present preparations showed that the saphenous stimulation at $\mathrm{C}$-fibre strength induced spike discharges in pectineus nerve during the 2 to $4 \mathrm{~s}$ period after the stimulus. The latter observation suggests that the saphenous nerve-evoked slow v.r.p. contains, at least in part, components of flexor reflexes.

A tachykinin antagonist, spantide (Rosell, 1986), depressed the saphenous nerve-evoked slow v.r.p., suggesting that SP and NKA may be involved as neurotransmitters in this slow response. A likely possibility is that SP and NKA are released from 


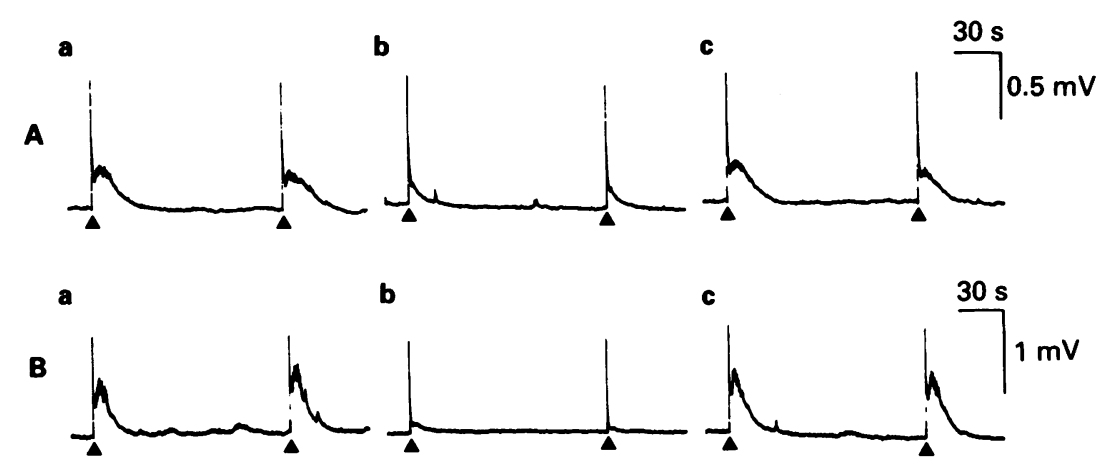

Figure 7 Effects of $\gamma$-aminobutyric acid (GABA) and muscimol on the reflex responses evoked by saphenous nerve stimulation. Isolated spinal cord-peripheral nerve preparation of 2 day-old (A) and 3 day-old (B) rats. Recordings and stimulation are as in Figure 4. (Aa) Control, (Ab) 3 min after adding $20 \mu \mathrm{M} \mathrm{GABA}$, (Ac) 15 min after washing out GABA. (Ba) Control, (Bb) 1 min after adding $0.2 \mu \mathrm{M}$ muscimol, (Bc) $40 \mathrm{~min}$ after washing out muscimol.

certain primary afferent $\mathbf{C}$ fibres upon stimulation of the saphenous nerve and produce slow excitatory postsynaptic potentials (e.p.s.ps) in dorsal horn neurones which, via synapses in the spinal cord, elicit a sustained depolarization of motoneurones (Otsuka \& Yanagisawa, 1988). In this connection, Cook et al. (1987) observed in rat spinal cord that brief inputs from peripheral afferent $C$ fibres can greatly increase the size of cutaneous receptive fields of dorsal horn neurones for prolonged periods, and suggested that this may be due to slow subthreshold excitation of dorsal horn neurones.

In the present study we used spantide at 4-16 $\mu \mathrm{M}$. Our previous study (Otsuka \& Yanagisawa, 1988) showed that spantide $16 \mu \mathrm{M}$ displays a considerable degree of specificity as a tachykinin antagonist, although it also antagonized bombesin (cf. Yachnis et al., 1984). However, the role of bombesin in the $\mathrm{C}$-fibre response in the present preparation is probably small because the amount of bombesin in the spinal cord was shown to be about one fiftieth of that of SP (McGregor et al., 1984). The $\mathrm{pA}_{2}$ values of spantide were estimated against various tachykinin agonists in various tissues. The estimated $\mathrm{pA}_{2}$ values varied between 5.2 and 6.9 , which suggests the existence of more than one class of spantide-susceptible tachykinin receptor (Chahl, 1985; Greiner, 1985; Featherstone et al., 1986; Buck \& Shatzer, 1988). In the newborn rat spinal cord we observed that spantide, 2-16 $\mu \mathrm{M}$, depressed the SP- and NKA-induced depolarization of the ventral root, and estimated the $\mathrm{pA}_{2}$ value of spantide against SP to be 5.4 (Otsuka \& Yanagisawa, 1988). This value probably represents mainly the $\mathrm{pA}_{2}$ values of tachykinin receptors of possibly more than one class located on spinal interneurones. On the other hand, Wienrich \& Harting (1985) found that the SP-induced depolarization of ventral roots was unaffected or potentiated by span- tide $10 \mu \mathrm{M}$ in the newborn rat spinal cord treated with tetrodotoxin, which may reflect different properties of tachykinin receptors located on motoneurones.

Immunohistochemical, autoradiographic and neurochemical studies show that there is a dense concentration of GABA terminals (Miyata \& Otsuka, 1975; Barber et al., 1978; Hunt et al., 1981), GABA receptors (Price et al., 1984; Young \& Kuhar, 1980), enkephalin-immunoreactive terminals (Hökfelt et al., 1977; Hunt et al., 1981) and opiate receptors (Atweh \& Kuhar, 1977) in superficial layers of the dorsal horn. Probably both GABA and enkephalins act as inhibitory neurotransmitters of spinal interneurones in this region. It is conceivable that an incoming primary afferent volley activates not only secondary sensory neurones but inhibitory interneurones containing GABA or enkephalins, and that these transmitters modulate the nociceptive input by presynaptic and/or postsynaptic inhibition. In support of this, the tail-pinch potential, i.e. the nociceptive reflex induced by tail-pinch and recorded from a lumbar ventral root of the isolated spinal cord-tail preparation, was potentiated by naloxone (Yanagisawa et al., 1984) and by bicuculline (Otsuka \& Yanagisawa, 1987a), suggesting that endogenous enkephalinergic and GABA-mediated mechanisms are involved. It should be noted, however, that the inhibitory mechanisms operated by GABA and enkephalins might be either tonic, acting as a background inhibition, or phasic, being activated by primary afferent stimulation.

The saphenous nerve-evoked slow v.r.p. was depressed by opioids, galanin, somatostatin, GABA and muscimol. The pharmacological properties of the slow v.r.p. are therefore similar to those of the capsaicin-induced nociceptive reflex observed in the isolated spinal cord-tail preparation of the newborn 
rat (Yanagisawa \& Otsuka, 1985; Yanagisawa et al., 1986a,b; Otsuka \& Yanagisawa, 1988), which is consistent with the assumption that both responses are evoked by $\mathrm{C}$-fibre stimulation. The effects of opioids may be relevant to the fact that $\mathrm{C}$-fibre-mediated nociception is particularly sensitive to morphine (Le Bars et al., 1976). Galanin, somatostatin and CGRP are known to occur in subpopulations of sensory $\mathrm{C}$ fibres (Hökfelt et al., 1976; Nagy et al., 1981; Ch'ng et al., 1985; Gibson et al., 1984; Gibbins et al., 1985). Based on the present findings of the peptide actions, it is conceivable that galanin, somatostatin and CGRP are released from sensory $\mathrm{C}$ fibres as neurotransmitters or co-transmitters and modulate nociceptive inputs in the substantia gelatinosa. The potentiating effect of CGRP on the saphenous nerveevoked slow v.r.p. is consistent with the observation of Woolf \& Wiesenfeld-Hallin (1986) that CGRP increased the excitability of the nociceptive flexion reflex. A possible mechanism of action of CGRP is the increase of SP release from C fibres (Oku et al., 1987), because the intrathecal application of CGRP did not affect the response to SP applied to the spinal cord in mice (Gamse \& Saria, 1986).

The present spinal cord-peripheral nerve prep-

\section{References}

AKAGI, H., KONISHI, S., OTSUKA, M. \& YANAGISAWA, M. (1985). The role of substance $P$ as a neurotransmitter in the reflexes of slow time courses in the neonatal rat spinal cord. Br. J. Pharmacol., 84, 663-673.

ATWEH, S.F. \& KUHAR, M.J. (1977). Autoradiographic localization of opiate receptors in rat brain. I. Spinal cord and lower medulla. Brain Res., 124, 53-67.

BARBER, R.P., VAUGHN, J.E., SAITO, K., MCLAUGHLIN, B.J. \& ROBERTS, E. (1978). GABAergic terminals are presynaptic to primary afferent terminals in the substantia gelatinosa of the rat spinal cord. Brain Res., 141, 35-55.

BUCK, S.H. \& SHATZER, S.A. (1988). Agonist and antagonist binding to tachykinin peptide NK-2 receptors. Life Sci., 42, 2701-2708.

CHAHL, L.A. (1985). Effects of substance P antagonists on the atropine-sensitive and atropine-resistant responses of guinea-pig ileum to substance P. Neurosci. Lett., 55, $35-40$.

CH'NG, J.L.C., CHRISTOFIDES, N.D., ANAND, P., GIBSON, S.J., ALLEN, Y.S., SU, H.C., TATEMOTO, K., MORRISON, J.F.B., POLAK, J.M. \& BLOOM, S.R. (1985). Distribution of galanin immunoreactivity in the central nervous system and the responses of galanin-containing neuronal pathways to injury. Neuroscience, 16, 343-354.

COOK, A.J., WOOLF, C.J., WALL, P.D. \& McMAHON, S.B. (1987). Dynamic receptive field plasticity in rat spinal cord dorsal horn following C-primary afferent input. Nature, 325, 151-153.

EKHOLM, J. (1967). Postnatal changes in cutaneous reflexes and in the discharge pattern of cutaneous and articular sense organ. A morphological and physiological study in the cat. Acta Physiol. Scand., Suppl. 297, 1-130. aration appears to offer many possibilities for further study of the spinal reflexes involving $\mathrm{C}$ fibres. For example, it should now be possible to examine pharmacological aspects of the effects of concomitant stimulation of A fibres on the C-fibre response. According to the gate control theory (Melzack \& Wall, 1965), stimulation of some A fibres would be expected to suppress the C-fibre reflex induced by saphenous nerve stimulation. It may also be possible to examine the effect of descending inhibition on C-fibre reflexes by stimulating appropriate nuclei in the brainstem (García-Arrarás et al., 1986). Furthermore, it will be possible to elaborate the present preparation to include various afferent and efferent pathways in the peripheral nervous system and study reflexes which are physiologically meaningful, such as autonomic reflexes.

We wish to thank Professor C.A. Nugent and Dr T. Murakoshi for helpful discussions and advice. We are also grateful to Dr M. Fujino, Central Research Division, Takeda Chemical Industries, Ltd., for the generous gift of spantide. Part of this work was supported by research grants from the Ministry of Education, Science and Culture, Japan, and from the Mitsubishi Foundation.
FEATHERSTONE, R.L., FOSBRAEY, P. \& MORTON, I.K.M. (1986). A comparison of the effects of three substance $P$ antagonists on tachykinin-stimulated $\left[{ }^{3} \mathrm{H}\right]$-acetylcholine release in the guinea-pig ileum. Br. J. Pharmacol., 87, 73-78.

FITZGERALD, M. (1985). The post-natal development of cutaneous afferent fibre input and receptive field organization in the rat dorsal horn. J. Physiol., 364, 1-18.

FITZGERALD, M. \& GIBSON, S. (1984). The postnatal physiological and neurochemical development of peripheral sensory C fibres. Neuroscience, 13, 933-944.

GAMSE, R. \& SARIA, A. (1986). Nociceptive behavior after intrathecal injections of substance $P$, neurokinin $A$ and calcitonin gene-related peptide in mice. Neurosci. Lett., 70, 143-147.

GARCÍA-ARRARÁS, J.E., MURAKOSHI, T., YANAGISAWA, M. \& OTSUKA, M. (1986). Descending inhibition of slow spinal reflex in an in vitro preparation of the newborn rat and its possible involvement in pain control. Brain Res., 379, 188-191.

GIBBINS, I.L., FURNESS, J.B., COSTA, M., MACINTYRE, I., HILLYARD, C.J. \& GIRGIS, S. (1985). Co-localization of calcitonin gene-related peptide-like immunoreactivity with substance $P$ in cutaneous, vascular and visceral sensory neurons of guinea pigs. Neurosci. Lett., 57, 125130.

GIBSON, S.J., POLAK, J.M., BLOOM, S.R., SABATE, I.M., MULDERRY, P.M., GHATEI, M.A., MCGREGOR, G.P., MORRISON, J.F.B., KELLY, J.S., EVANS, R.M. \& ROSENFELD, M.G. (1984). Calcitonin gene-related peptide immunoreactivity in the spinal cord of man and of eight other species. J. Neurosci., 4, 3101-3111. 
GREENE, E.C. (1968). Anatomy of The Rat. New York, London: Hafner Publishing Company.

GREINER, H.E. (1985). In vitro binding of ${ }^{3} \mathrm{H}$-substance $\mathrm{P}$ and ${ }^{3} \mathrm{H}$-eledoisin to bovine dorsal horn, rat cortex and rat spinal cord. In Tachykinin Antagonists. ed. Håkanson, R. \& Sundler, F., pp. 333-342. Amsterdam, New York, Oxford: Elsevier.

HEYMAN, I. \& RANG, H.P. (1985). Depolarizing responses to capsaicin in a subpopulation of rat dorsal root ganglion cells. Neurosci. Lett., 56, 69-75.

HÖKFELT, T., ELDE, R., JOHANSSON, O., LUFT, R., NILSSON, G. \& ARIMURA, A. (1976). Immunohistochemical evidence for separate populations of somatostatin-containing and substance P-containing primary afferent neurons in the rat. Neuroscience, 1 , 131-136.

HÖKFELT, T., LJUNGDAHL, A., TERENIUS, L., ELDE, R. \& NILSSON, G. (1977). Immunohistochemical analysis of peptide pathways possibly related to pain and analgesia: Enkephalin and substance P. Proc. Natl. Acad. Sci. U.S.A., 74, 3081-3085.

HUA, X.Y., THEODORSSON-NORHEIM, E., BRODIN, E., LUNDBERG, J.M. \& HÖKFELT, T. (1985). Multiple tachykinins (neurokinin $A$, neuropeptide $K$ and substance $P$ ) in capsaicin-sensitive sensory neurons in the guinea-pig. Regul. Pept., 13, 1-19.

HUNT, S.P., KELLY, J.S., EMSON, P.C., KIMMEL, J.R., MILLER, R.J. \& WU, J-Y. (1981). An immunohistochemical study of neuronal populations containing neuropeptides or $\gamma$-aminobutyrate within the superficial layers of the rat dorsal horn. Neuroscience, 6, 18831898.

JANCSÓ, G., KIRÁLY, E., JOÓ, F., SUCH, G. \& NAGY, A. (1985). Selective degeneration by capsaicin of a subpopulation of primary sensory neurons in the adult rat. Neurosci. Lett., 59, 209-214.

KENINS, P. (1982). Responses of single nerve fibres to capsaicin applied to the skin. Neurosci. Lett., 29, 83-88.

KONISHI, S. (1982). Electrophysiology of mammalian spinal cord and sympathetic ganglia in vitro. In Advances in Pharmacology and Therapeutics II. Vol. 2, ed. Yoshida, H., Hagihara, Y. \& Ebashi, S., pp. 255-260. Oxford: Pergamon Press.

KUDO, N. \& YAMADA, T. (1985). Development of the monosynaptic stretch reflex in the rat: An in vitro study. J. Physiol., 369, 127-144.

LEAH, J.D., CAMERON, A.A. \& SNOW, P.J. (1985). Neuropeptides in physiologically identified mammalian sensory neurones. Neurosci. Lett., 56, 257-263.

LE BARS, D., GUILBAUD, G., JURNA, I. \& BESSON, J.M. (1976). Differential effects of morphine on responses of dorsal horn lamina $\mathrm{V}$ type cells elicited by $\mathrm{A}$ and $\mathrm{C}$ fibre stimulation in the spinal cat. Brain Res., 115, 518524.

MARSH, S.J. (1985). Depolarization of rat vagal C-fibres and sensory neurones by capsaicin in vitro. J. Physiol., 360, $14 \mathrm{P}$.

MCGREGOR, G.P., GIBSON, S.J., SABATE, I.M., BLANK, M.A., CHRISTOFIDES, N.D., WALL, P.D., POLAK, J.M. \& BLOOM, S.R. (1984). Effect of peripheral nerve section and nerve crush on spinal cord neuropeptides in the rat: increased VIP and PHI in the dorsal horn. Neuroscience, 13, 207-216.
MELZACK, R. \& WALL, P.D. (1965). Pain mechanisms: A new theory. Science, 150, 971-979.

MIYATA, Y. \& OTSUKA, M. (1975). Quantitative histochemistry of $\gamma$-aminobutyric acid in cat spinal cord with special reference to presynaptic inhibition. $J$. Neurochem., 25, 239-244.

NAGY, J.I., HUNT, S.P., IVERSEN, L.L. \& EMSON, P.C. (1981). Biochemical and anatomical observations on the degeneration of peptide-containing primary afferent neurons after neonatal capsaicin. Neuroscience, 6, 1923-1934.

OKU, R., SATOH, M., FUJII, N., OTAKA, A., YAJIMA, H. \& TAKAGI, H. (1987). Calcitonin gene-related peptide promotes mechanical nociception by potentiating release of substance $\mathbf{P}$ from the spinal dorsal horn in rats. Brain Res., 403, 350-354.

OTSUKA, M. \& YANAGISAWA, M. (1987a). Effect of a substance $P$ antagonist on capsaicin-induced nociceptive reflex in the isolated spinal cord-tail preparation of the rat. Acta Physiol. Hung., 69, 363-366.

OTSUKA, M. \& YANAGISAWA, M. (1987b). The roles of neuropeptides in spinal nociceptive mechanisms: new approaches using isolated CNS preparations. In Pharmacology. Proc. 10th Int. Congr. Pharmacol. ed. Rand, M.J. \& Raper, C. pp. 211-214, Amsterdam: Elsevier.

OTSUKA, M. \& YANAGISAWA, M. (1988). Effect of a tachykinin antagonist on a nociceptive reflex in the isolated spinal cord-tail preparation of the newborn rat. $J$. Physiol., 395, 255-270.

POST, C., BUTTERWORTH, J.F., STRICHARTZ, G.R., KARLSSON, J.A. \& PERSSON, C.G.A. (1985). Tachykinin antagonists have potent local anaesthetic actions. Eur. J. Pharmacol., 117, 347-354.

PRICE, G.W., WILKIN, G.P., TURNBULL, M.J. \& BOWERY, N.G. (1984). Are baclofen-sensitive $\mathrm{GABA}_{\mathrm{B}}$ receptors present on primary afferent terminals of the spinal cord. Nature, 307, 71-74.

ROSELL, S. (1986). Tachykinins and tachykinin antagonists In Substance $P$ - Metabolism and Biological Actions, ed. Jordan, C.C. \& Oehme, P., pp. 95-97. London, Philadelphia: Taylor \& Francis.

SAITO, K. (1979). Development of spinal reflexes in the rat fetus studied in vitro. J. Physiol., 294, 581-594.

SURPRENANT, A., NORTH, R.A. \& KATAYAMA, Y. (1987). Observations on the actions of substance $\mathbf{P}$ and [D-

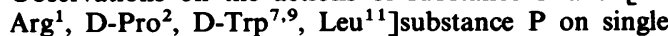
neurones of the guinea pig submucous plexus. Neuroscience, 20, 189-199.

WIENRICH, M. \& HARTING, J. (1985). Effects of putative tachykinin-antagonists on the slow ipsilateral ventral root potential in the isolated spinal cord preparation of the neonatal rat. In Tachykinin Antagonists. ed. Håkanson, R. \& Sundler, F., pp. 367-376. Amsterdam, New York, Oxford: Elsevier.

WOOLF, C. \& WIESENFELD-HALLIN, Z. (1986). Substance $P$ and calcitonin gene-related peptide synergistically modulate the gain of the nociceptive flexor withdrawal reflex in the rat. Neurosci. Lett., 66, 226-230.

YACHNIS, A.T., CRAWLEY, J.N., JENSEN, R.T., MCGRANE, M.M. \& MOODY, T.W. (1984). The antagonism of bombesin in the CNS by substance $P$ analogues. Life Sci., 35, 1963-1969.

YANAGISAWA, M., MURAKOSHI, T., TAMAI, S. \& OTSUKA, $M$. (1984). Tail-pinch method in vitro and the effects of 
some antinociceptive compounds. Eur. J. Pharmacol, 106, 231-239.

YANAGISAWA, M. \& OTSUKA, M. (1985). The effect of a substance $P$ antagonist on the capsaicin-induced nociceptive reflex in the isolated spinal cord-tail preparation of the neonatal rat. Neurosci. Res., Suppl. 1, S101.

YANAGISAWA, M., OTSUKA, M. \& GARCÍA-ARRARÁS, J.E. (1986a). Effects of GABA and GABA-related drugs on the capsaicin-induced nociceptive reflex in the isolated spinal cord-tail preparation of the newborn rat. Neurosci. Res., Suppl. 3, S127.

YANAGISAWA, M., YAGI, N., OTSUKA, M., YANAIHARA, C. \& YANAIHARA, N. (1986b). Inhibitory effects of galanin on the isolated spinal cord of the newborn rat. Neurosci. Lett., 70, 278-282.

YOUNG III, W.S. \& KUHAR, M.J. (1980). Radiohistochemical localization of benzodiazepine receptors in rat brain. $J$. Pharmacol. Exp. Ther., 212, 337-346.

(Received November 14, 1988

Revised, March 15, 1989 Accepted May 15, 1989) 